\title{
Dual-Phase Hot-Press Forming Alloy
}

\author{
H. L. Yi ${ }^{a}$ S. Ghosh ${ }^{a}$ H. K. D. H. Bhadeshia ${ }^{a, b}$ \\ ${ }^{a}$ Graduate Institute of Ferrous Technology, Pohang University of Science and \\ Technology, Pohang 790-784, Republic of Korea \\ ${ }^{\mathrm{b}}$ Materials Science and Metallurgy, University of Cambridge, Cambridge CB2 \\ 3QZ, U.K.
}

\begin{abstract}
Hot-press forming steels are formed in a fully austenitic state followed by diequenching in order to generate martensite and achieve a strong steel. The ductility however, tends to be limited. We explore in this work a novel steel design in which the forming operation is in the two-phase austenite and ferrite field, so that the quenching results in a dual-phase ferrite and martensite microstructure at ambient temperature. It is demonstrated that better properties are achieved. The interpretation of the mechanisms of deformation during tensile testing indicate that the ductility can be further enhanced without compromising strength. The new steel also can be heated to temperature which is lower than that used for conventional hot-press forming steels, before transfer into the forming press.
\end{abstract}

Key words: Hot press-forming, dual phase steel, formability, grain refinement, martensite

\section{Introduction}

One application of strong steels in the context of automobiles is to enhance passenger safety by resisting damage to the passenger compartment during collisions. There are many varieties of such steels, for example those which are TRIP-assisted [1-6] or the dual-phase steels which are nicely reviewed in [7]. These steels have to be formable and that requirement is difficult to achieve when the strength exceeds about $1000 \mathrm{MPa}$. Strong steels also suffer from an

Email addresses: hityihl@postech.ac.kr, corresponding author (H. L. Yi), sadhanghosh@postech.ac.kr (S. Ghosh), hkdb@cam.ac.uk (H. K. D. H. Bhadeshia). 
exaggerated change in shape due to the relaxation of elastic stresses when the steel is removed from the forming press [8].

One solution to these difficulties was the invention in Sweden $[9,10]$ of the process known as hot-press forming, in which a hot sheet of steel in its austenitic state, is fed into a forming press with water-cooled dies which quench the material into a martensitic state. Following austenitisation at about $900^{\circ} \mathrm{C}$ $[11,12]$, the steel is transferred to the press and the deformation occurs at high temperatures approximately in the range $800-600^{\circ} \mathrm{C}$ [13] where the steel is soft and formability limitations insignificant. The quenching produces already-formed components with strength in the range 1200-1600 MPa. There is little or no change in shape when the component is removed from the press. The steels typically have a composition Fe-0.22C, 1-2 wt\% Mn (depending on whether the steel also is alloyed with boron) and other trace elements to give a martensite-start temperature of about $400^{\circ} \mathrm{C}$ [14]. The steel in its final condition after hot-press forming is fully martensitic and has a ductility (total elongation) of approximately $6-8 \%$. One variant of the process is warm forming [15], where the maximum temperature to which the steel is heated can be as low as $600^{\circ} \mathrm{C}$ in order to minimise springback and oxidation. However, the strength achieved in this case is much lower than in hot-press forming because the steel is not austenitic during the forming process.

The purpose of the present work was to explore another option with the hope of improving ductility in the press-formed condition whilst maintaining the strength. An alloy was designed so that it consists of a mixture of allotriomorphic ferrite and austenite at the forming temperature, so that subsequent quenching leads to a dual-phase steel. A potential advantage of this mixture of allotriomorphic ferrite and martensite could be that the latter phase occurs in a finer state than in fully martensitic steels; this in itself should improve the resistance of the martensite to cracking [16-18].

\section{Experimental Method}

The steel studied has the chemical composition

$$
\mathrm{Fe}-0.40 \mathrm{C}-0.26 \mathrm{Si}-2.02 \mathrm{Mn}-2.50 \mathrm{Al}-0.018 \mathrm{P}-0.0036 \mathrm{~S}-0.0048 \mathrm{~N} \text { wt\% }
$$

and its calculated phase diagram is in Fig. 1a. The combination of alloying elements, especially the aluminium, ensures that the alloy has a large ferrite content at elevated temperatures. The alloy in fact was originally designed for a different purpose, the so-called $\delta$-TRIP concept [19-21] where the allotriomorphic ferrite present in conventional TRIP-assisted steels $[4,5]$ is replaced by $\delta$-ferrite created during solidification. However, effects associated with non- 
equilibrium cooling prevented success [20] and a different approach was necessary in that application. Nevertheless, by serendipity, the alloy proved useful to explore the dual-phase hot-press forming studied here.

The alloy was manufactured as $34 \mathrm{~kg}$ ingot of $100 \times 170 \times 230 \mathrm{~mm}$ dimensions using a vacuum furnace. The ingot was reheated to $1200^{\circ} \mathrm{C}$ for rough rolling to make 25-30 mm slabs followed by air cooling. These slabs were then reheated to $1200^{\circ} \mathrm{C}$ and hot-rolled to $3 \mathrm{~mm}$ in thickness; $1.2 \mathrm{~mm}$ thick sheets were then produced by cold rolling. Optical microscopy samples were prepared using standard methods and etched in $2 \%$ nital. Higher resolution observations was done using a field-emission scanning electron microscope operating at $10 \mathrm{kV}$ accelerating voltage. Heat treatments were conducted on a simulator, CCTAY, made by ULVAC-RIKO. The cold rolled sheets for tensile testing were heated in a nitrogen atmosphere at $840,860,880$ and $900^{\circ} \mathrm{C}$ respectively for $3 \mathrm{~min}$ at the heating rate $20^{\circ} \mathrm{Cs}^{-1}$, followed by quenching at $-40^{\circ} \mathrm{Cs}^{-1}$ using nitrogen. The sub-size tensile specimens were machined according to ASTM standard E8M-00 with elongation recorded over a gauge length $10 \mathrm{~mm}$ and a strain rate of approximately $3.3 \times 10^{-3} \mathrm{~s}^{-1}$.

Conventional hot-rolling was conducted between $1200-900^{\circ} \mathrm{C}$; the fact that ferrite coexists with austenite at all temperatures in this range leads to a significant refinement, a grain size of just $3.1 \pm 0.2 \mu \mathrm{m}$ without using any thermomechanical processing (Fig. 1b). The phenomenon is well-established in the field of superplasticity where two phase mixtures can resist coarsening during deformation [22]. The cold-rolled structure is illustrated in (Fig. 1c).

\section{Results and Discussion}

Metallographic observations confirmed the dual-phase ferrite $(\alpha)$ and martensite $\left(\alpha^{\prime}\right)$ microstructure obtained following heat-treatment at 840, 860, 880 and $900^{\circ} \mathrm{C}$ for $3 \mathrm{~min}$ followed by quenching, Fig. 2. Quantitative data are presented in Table 1, which show as expected from the phase diagram, that the fraction of ferrite decreases as the maximum heat-treatment temperature is increased. The size scales were characterised using standard metallographic theory [23], with the mean lineal intercepts $(\bar{L})$ in the two phases given by

$$
\bar{L}_{\alpha}=\frac{L V_{V}^{\alpha}}{N^{\alpha}} \quad \bar{L}_{\alpha^{\prime}}=\frac{L V_{V}^{\alpha^{\prime}}}{N^{\alpha^{\prime}}}
$$

where $V_{V}$ and $N$ represent the volume fraction and number of grains respectively of the phase identified by the superscript. The observed grain sizes of the ferrite and of the martensite islands are remarkably small given the simple heat-treatment and the absence of any thermomechanical processing, Table 1. 
Table 1

Quantitative metallographic data, and the carbon content of the martensite as estimated by mass balance from the average concentration.

\begin{tabular}{lllll}
\hline Heat-treatment $T /{ }^{\circ} \mathrm{C}$ & $100 V_{V}^{\alpha}$ & $\mathrm{C}_{\alpha^{\prime}} / \mathrm{wt} \%$ & $\bar{L}_{\alpha} / \mu \mathrm{m}$ & $\bar{L}_{\alpha^{\prime}} / \mu \mathrm{m}$ \\
\hline 840 & $38 \pm 5$ & $0.64 \pm 0.05$ & $1.2 \pm 0.1$ & $1.7 \pm 0.3$ \\
860 & $34 \pm 9$ & $0.60 \pm 0.07$ & $1.1 \pm 0.1$ & $1.9 \pm 0.1$ \\
880 & $32 \pm 6$ & $0.58 \pm 0.05$ & $1.1 \pm 0.2$ & $2.4 \pm 0.2$ \\
900 & $26 \pm 6$ & $0.54 \pm 0.05$ & $1.0 \pm 0.1$ & $2.5 \pm 0.4$ \\
\hline
\end{tabular}

Tensile test results are illustrated in Fig. 3 together with a comparison against some published data. There are a number of features which are striking, first that the yield strength is quite low, around $400 \mathrm{MPa}$, followed by workhardening. This kind of behaviour is expected in dual-phase steels [24-26] consisting of two phases which have quite different yield strengths. The application of stress at first causes yielding in the softer phase only, but because the ferrite does not occupy the entire specimen, it yields at a stress less than that of the ferrite isolation. This explains the very low macroscopic yield strength observed.

It is only after the ferrite has work hardened to be able to transfer sufficient load on to the stronger martensite that the latter begins to deform plastically. It is in this way that high-strength is achieved. However, fracture will occur when the martensite is no longer able to support plastic strain.

The surprising trend in the data illustrated in Fig. 3c is that the total elongation increases as the heat-treatment temperature is reduced, in spite of the fact that the material at the same time becomes stronger. A recent idea explaining the ductility of another microstructure consisting of a hard and soft phase is that failure occurs in a tensile test when percolation is lost through the ductile phase [27, 28]. Percolation theory is well-established [29] and was used in the present case to estimate the volume fraction of equiaxed ferrite required to ensure continuity in the microstructures generated. It was found that a minimum of $V_{V}^{\alpha}=0.29$ is needed so that the ferrite can be traversed in the microstructure without interruption. This is likely to be an underestimate given that a uniform grain size and distribution is assumed. It is interesting that the volume fractions of ferrite listed in Table 1 are quite close to the percolation fraction for the lowest ductility samples, i.e., those heat treated at 880 and $900^{\circ} \mathrm{C}$. Fig 4 shows cracks in the vicinity of the fracture surfaces of broken tensile samples. In the case of the sample heat-treated at $840^{\circ} \mathrm{C}$, which had the highest ferrite content and was ultimately the strongest, it is evident that the ferrite is able to accommodate a lot of damage before fracture 
propagates, whereas this is not so for the $880^{\circ} \mathrm{C}$ sample where large cracks are able to develop without much hindrance within the martensite.

Referring back to Fig. 3c, the best total elongation achieved here are slightly better than for data corresponding to conventional hot-press forming martensitic steels [14, 30-32]. However, with the interpretations presented above, it should be possible to further improve the dual-phase steel by reducing the carbon concentration to $0.3 \mathrm{wt} \%$ in order to make the martensite somewhat softer and to allow a greater quantity of ferrite relative to the percolation threshold. It remains to be seen as to how much tolerance there is for an increase in ferrite content since there must come a point where strength is reduced.

Finally, it is worth emphasising that the total elongation achieved for an ultimate tensile strength approaching $1550 \mathrm{MPa}$ is much greater than the $6 \%$ for an established dual-phase steel with a tensile strength of $1400 \mathrm{MPa}$ [31], and is comparable to that for another dual-phase steel which has an elongation of $9 \%$ but at a much lower tensile strength of $1000 \mathrm{MPa}$ [31]. This is undoubtedly because of the fine scale of the microstructure obtained in the present work, by hot-rolling in the two-phase field. In terms of the uniform elongation (Fig. 3d), the steel investigated here significantly outperforms the fully martensitic variants reported in the published literature [14, 30-32].

\section{Conclusions}

It has been demonstrated that it is possible to achieve a steel consistent with the requirement of hot-press forming, where the structure at the forming temperature consists of a mixture of allotriomorphic ferrite and austenite, with the latter changing into martensite on quenching. This is in contrast to the fully martensitic variants in use today.

It may be a commercial advantage that the maximum heat treatment temperature can be reduced to $840^{\circ} \mathrm{C}$, which is at least $20-60^{\circ} \mathrm{C}$ lower than convention.

Furthermore, the total elongations recorded for the dual-phase steel are slightly better than those of the fully martensitic alloys, and our interpretation of the mechanisms of ductility and strength suggest that there is room for improvement. In terms of uniform elongation, the dual-phase steel significantly outperforms the fully martensitic counterparts. 


\section{Acknowledgments}

We are grateful to Dongwei Fan for useful discussions, to Professor Hae-Geon Lee for laboratory facilities at GIFT, and to POSCO for the Steel Innovation Programme. Support from the World Class University Programme of the National Research Foundation of Korea, Ministry of Education, Science and Technology, project number R32-2008-000-10147-0 is gratefully acknowledged.

\section{References}

[1] O. Matsumura, Y. Sakuma, H. Takechi, Transactions of the Iron and Steel Institute of Japan 27 (1987) 570-579.

[2] O. Matsumura, Y. Sakuma, H. Takechi, Scripta Metallurgica 27 (1987) 1301-1306.

[3] Y. Sakuma, O. Matsumura, H. Takechi, Metallurgical \& Materials Transactions A 22 (1991) 489-498.

[4] P. J. Jacques, Current Opinion in Solid State and Materials Science 8 (2004) 259-265.

[5] B. DeCooman, Current Opinion in Solid State and Materials Science 8 (2004) 285-303.

[6] H. K. D. H. Bhadeshia, R. W. K. Honeycombe, Steels: Microstructure and Properties, 3rd edition, Butterworth-Heinemann, London, 2006.

[7] W. S. Owen, Metals Technology 7 (1980) 1-13.

[8] N. Kuhn, Journal of the Australian Institute of Metals 12 (1967) 71-76.

[9] Norrbottens Jaernverk A. B., Manufacturing of a hardened steel article, Patent GB1490535, Norrbottens Järnverk AB, Sweden, 1977.

[10] G. Berglund, in: M. O. K. Steinhoff, B. Prakash (Eds.), 1st International Conference on Hot sheet metal forming of high-performance steel, CHS2, GRIPS media GmbH, Kassel, Germany, October 22-24, 2008, pp. 1-3.

[11] D. Berglund, K. Amundsson, L.-O. Hellgren, in: M. O. K. Steinhoff, B. Prakash (Eds.), 1st International Conference on Hot sheet metal forming of high-performance steel, CHS2, GRIPS media GmbH, Kassel, Germany, 2008, pp. 175-177.

[12] K. Kusumi, S. Yamamoto, T. Takeshita, M. Abe, in: K. S. M. Oldenburg, B. Prakash (Eds.), 2nd International Conference on Hot sheet metal forming of high-performance steel, CHS2, Verlag Wissenschaftliche Scripten, Luleå, Sweden, 2009, pp. 165-174.

[13] P. Hein, J. Wilsius, Steel Research International 79 (2008) 85-91.

[14] D. W. Fan, H. S. Kim, B. C. D. Cooman, Steel Research International 80 (2009) 241-248. 
[15] K. Mori, S. Maki, Y. Tanaka, CIRP Annals - Manufacturing Technology 54 (2005) 209-212.

[16] H. K. D. H. Bhadeshia, D. V. Edmonds, Metal Science 17 (1983) 411-419.

[17] H. K. D. H. Bhadeshia, D. V. Edmonds, Metal Science 17 (1983) 420-425.

[18] S. Chatterjee, H. K. D. H. Bhadeshia, Materials Science and Technology 22 (2006) 645-649.

[19] S. Chatterjee, M. Murugananth, H. K. D. H. Bhadeshia, Materials Science and Technology 23 (2007) 819-827.

[20] H. L. Yi, S. K. Ghosh, W. J. Liu, K. Y. Lee, H. K. D. H. Bhadeshia, Materials Science and Technology 26 (2010) in press. Preprint available on http://cml.postech.ac.kr/a.pdf.

[21] H. L. Yi, K. Y. Lee, H. K. D. H. Bhadeshia, Materials Science and Technology 26 (2010) in press. Preprint available on http://cml.postech.ac.kr/b.pdf.

[22] Y. Maehara, T. G. Langdon, Materials Science \& Engineering A 128 (1990) 1-13.

[23] R. T. DeHoff, F. N. Rhines, Quantitative Microscopy, McGraw Hill, New York, 1968.

[24] Y. Tomota, K. Kuroki, T. Mori, I. Tamura, Materials Science and Engineering 24 (1976) 85-94.

[25] S. T. Mileiko, Journal of Materials Science 4 (1981) 974-977.

[26] H. K. D. H. Bhadeshia, D. V. Edmonds, Metal Science 14 (1980) 41-49.

[27] H. K. D. H. Bhadeshia, Materials Science and Engineering A 481-482 (2008) 36-39.

[28] H. K. D. H. Bhadeshia, Proceedings of the Royal Society of London A 466 (2010) 3-18.

[29] E. J. Garboczi, K. A. Snyder, J. F. Douglas, M. F. Thorpe, Physical Review E 52 (1995) 819-828.

[30] M. Suehiro, J. Maki, K. Kusumi, M. Ohgami, T. Miyakoshi, Properties of aluminium-coated steels for hot-forming, Technical Report 88: 16-21, Nippon Steel Corporation Technical Report, 2003.

[31] M. Naderi, Hot stamping of ultra-high strength steels, Ph.D. thesis, RWTH Aachen, Germany, 2007.

[32] D. W. Fan, H. S. Kim, B. C. D. Cooman, in: K. S. M. Oldenburg, B. Prakash (Eds.), Hot sheet metal forming of high-performance steel, 2nd conference, Verlag Wissenschaftliche Scripten, Auerbach, Germany, 2009, pp. 7-16.

[33] NPL, MTDATA, Software, National Physical Laboratory, Teddington, U.K., 2006. 


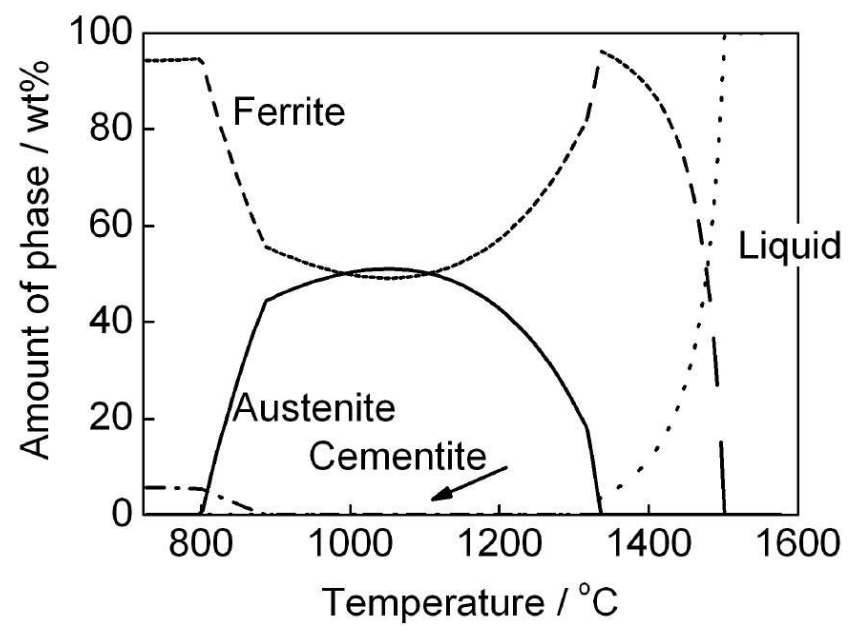

(a)
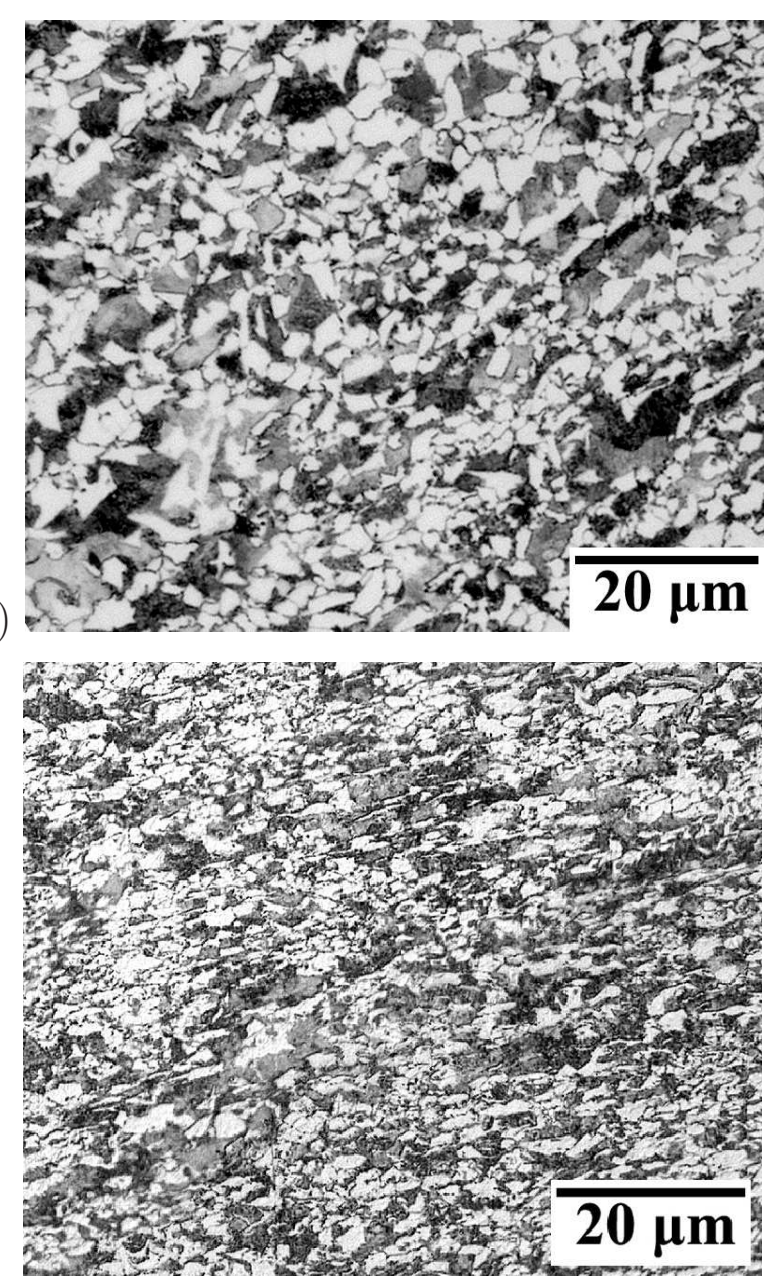

Fig. 1. (a) Phase diagram calculated using MTDATA [33] and the TCFE (version 1.2) database. (b) Optical microstructure in the hot-rolled state. (c) Optical microstructure in the cold-rolled state. 
(a)
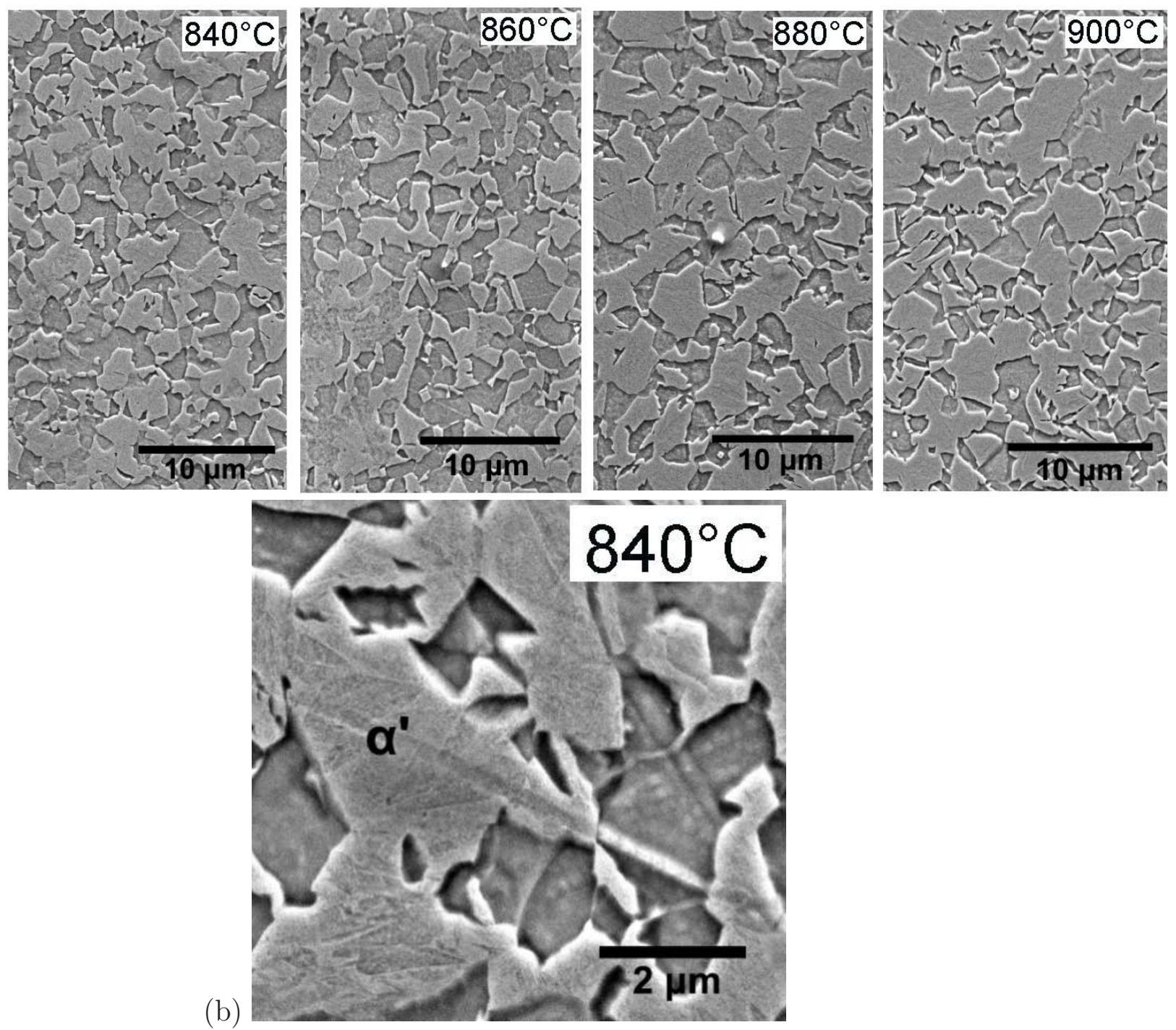

Fig. 2. (a) Microstructures after heat treatment at the temperatures indicated followed by quenching. The light-etching regions which seem to protrude are martensitic. (b) Scanning electron micrograph showing martensite at higher resolution. 


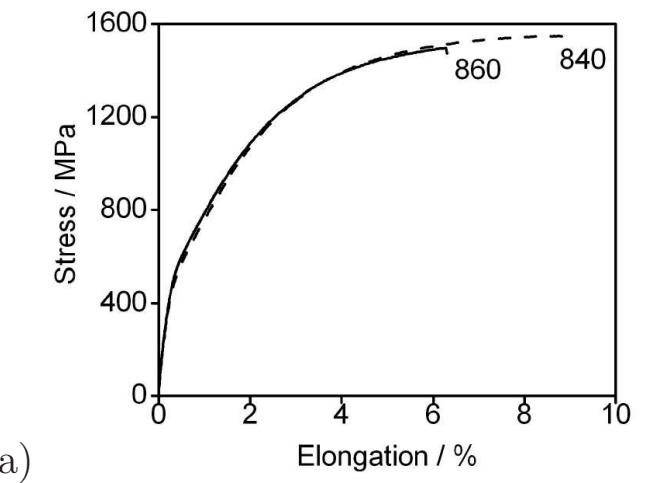

(b)
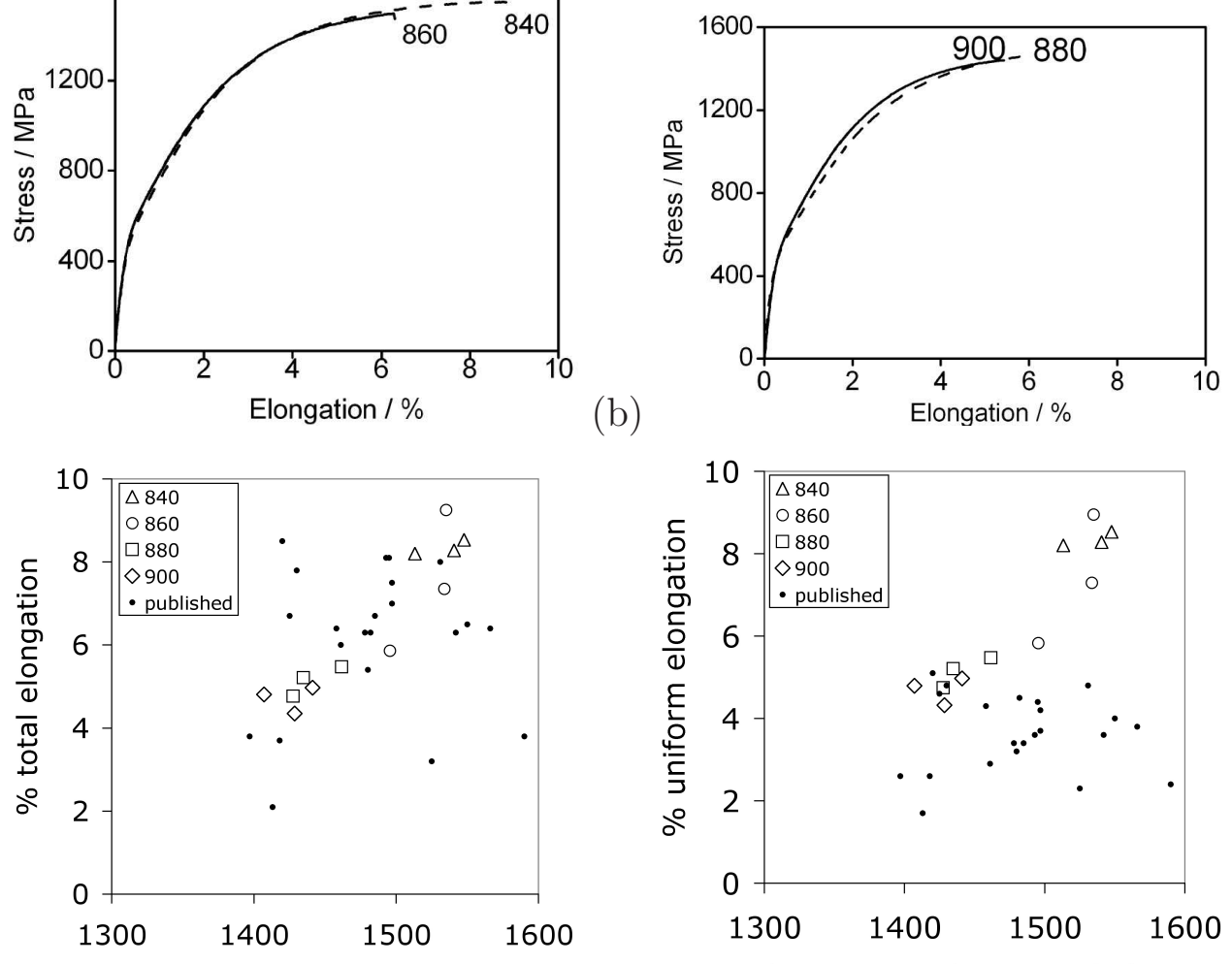

(c)

Ultimate tensile strength / $\mathrm{MPa}$

(d)

Ultimate tensile strength / $\mathrm{MPa}$

Fig. 3. (a,b) Tensile test data. (c,d) Comparison of total and uniform elongation respectively, against strength. The published data are from [14, 30-32]. 


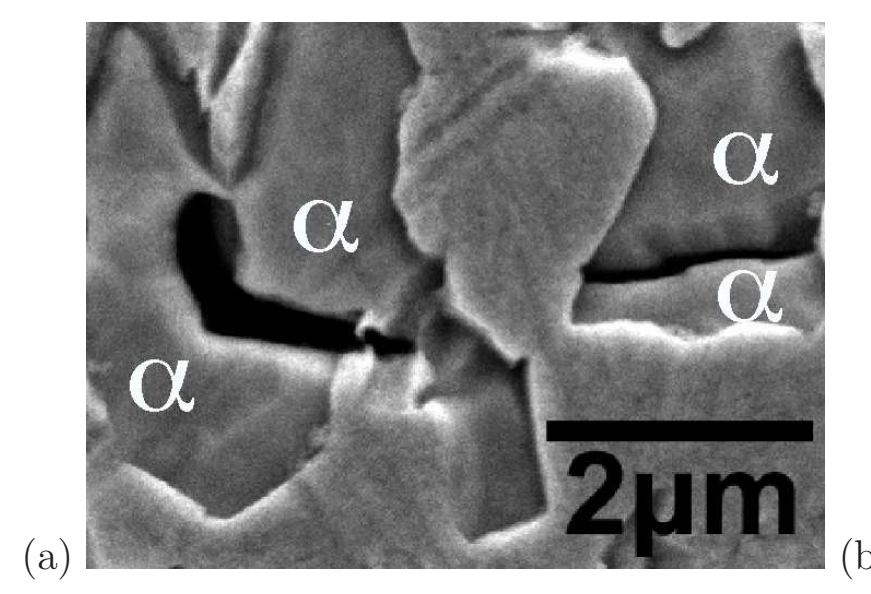

(b)

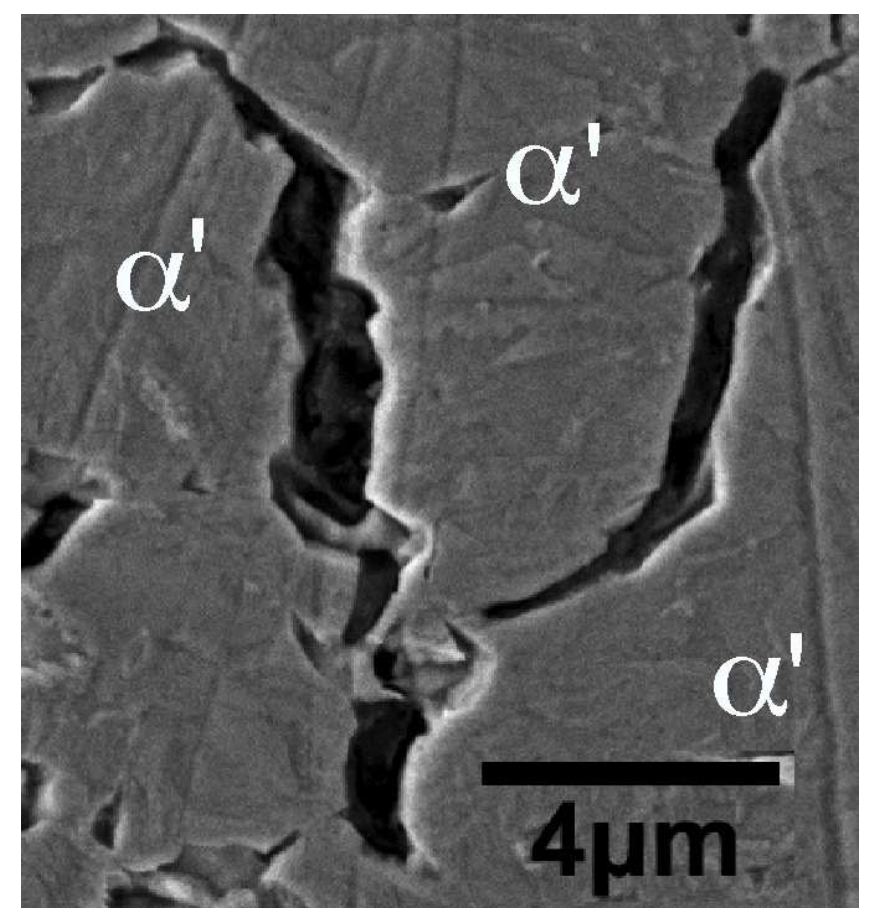

Fig. 4. Typical cracks near under the fracture surface of broken tensile test specimens. (a) Non-propagating cracks in the ferrite, sample heat-treated at $840^{\circ} \mathrm{C}$. (b) Cracks in large martensite regions in sample heat-treated at $880^{\circ}$. 